\title{
Plexo. Una travesía multisensorial
}

\author{
Plexo. A multi sensory journey
}

\author{
- Fernando García Amen \\ VidiaLab, Facultad de Arquitectura, UdelaR. \\ Uruguay \\ efe@farq.edu.uy \\ - Marcelo Payssé Álvarez \\ DepInfo, Facultad de Arquitectura, UdelaR. \\ Uruguay \\ paysse@farq.edu.uy
}

\author{
Juan Pablo Portillo \\ VidiaLab, Facultad de Arquitectura, UdelaR. \\ Uruguay \\ jppotrillo@farq.edu.uy \\ - Raúl Felipe Buzó \\ VidiaLab, Facultad de Arquitectura, UdelaR. \\ Uruguay \\ raulbuzo@farq.edu.uy
}

\begin{abstract}
This paper intends to reflect, from an educational point, on the concepts and technology that supports the traditonal "architecture trip" of the University of the Republic. It is necessary to clarify that at the time of this presentation this work is still in progress, and its final results may not be defined yet, but can be estimated based on the feedback received. Definitive conclusions could only be determined in the upcoming months.
\end{abstract}

Keywords: Accessibility, Geoposition, Ubiquitous Computing, Teaching, Travel

\section{Introducción}

Desde hace setenta y un años, cada generación de estudiantes de arquitectura de la Universidad de la República, compuesta por estudiantes apenas egresados o por egresar, realiza anualmente un viaje autogestionado que se financia mediante la venta de rifas. Este viaje, que dura alrededor de ocho meses, transita más de treinta países, recorriendo diferentes destinos en Asia, África, Norteamérica y Europa.

Esta travesía se realiza bajo la tutela y orientación académica y curricular de un equipo docente que se elige por parte de los estudiantes en base a la evaluación de diferentes propuestas académicas.

En esta oportunidad, dicho equipo se encuentra formado por un colectivo multidisciplinar compuesto por miembros de varias cátedras, abarcando el diseño, la teoría de la arquitectura, los medios de expresión, y las tecnologías de la información.

Plexo es la palabra elegida para designar al proyecto académico multidisciplinar del año 2015. El plexo es una imagen mental: una red formada por varias tramas o terminaciones nerviosas entrelazadas. Todos los plexos presentan entrelazamientos complejos de mallas más o menos dinámicas que forman variados y numerosos pliegues, uniones, y separaciones.

La clave fundamental de comprensión es la interacción, y la interrelación permanente, con un eje vertebrador común. Este eje es transversal a todos los aspectos de formación de los arquitectos, abordando la instrumentación sistemática de clases presenciales, las visitas regulares a universidades y estudios de arquitectos reconocidos, y el reconocimiento sensorial y vivencial de las obras canónicas de arquitectura a lo largo y ancho del planeta.

\section{Objetivos}

El objetivo general de este proyecto es:

- mostrar las claves operativas que sustentan didácticamente la dinámica del viaje haciendo especial énfasis en sus innovaciones tecnológicas.

Los objetivos específicos son:

- transmitir una experiencia que puede ser replicable en otros contextos socioeducativos similares;

- profundizar en el uso inteligente de las tecnologías de la información en su aplicación más didáctica; y

- legitimar esta experiencia mediante su socialización en un ámbito internacionalmente reconocido como lo es SiGraDi.

\section{Metodología}

La premisa fundamental de este planteo es romper con los viejos cánones, prejuicios y convencionalismos que moldearon a través de los años el Viaje de Arquitectura tradicional, proponiendoalternativas estratégicas para solventar problemas conocidos pero nunca abordados con anterioridad. 
En tal sentido, se propusieron y desarrollaron algunas herramientas que sirvieron como insumos operativos. Se dividirán para su exposición en este resumen de acuerdo al alcance de cada instrumento, y al grupo objetivo al que están orientados, de acuerdo a su escala y especificidad:

\section{M1. Estudiantes en viaje (a escala individual)}

Se abordó en primera medida el estudio del viajero individual. Tomando como antecedente la experiencia obtenida en el proyecto académico del año 2011 titulado "Viaje 2.0. Un moleskine digital", se trabajó en la confección del instrumento homónimo.
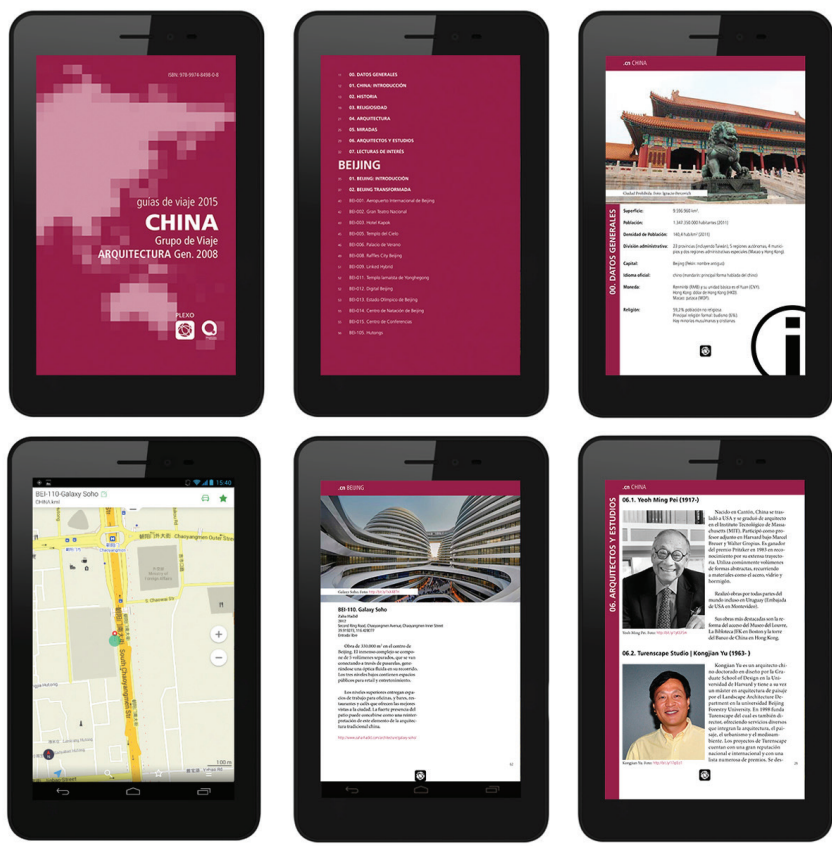

Figura 1: Moleskine en funcionamiento, mostrando contenidos, georreferencias y reseñas.

A modo de definición técnica, cada moleskine digital es un dispositivo electrónico personal -en formato tablet-, que contiene todos los insumos académicos requeridos para la realización del viaje. De este modo, representa la sustitución de las tradicionales guías de viaje elaboradas por el equipo docente en formato impreso, suplantándolas por versiones digitales interactivas, que pueden ser descargadas libremente de la web y que reseñan más de tres mil quinientas obras de arquitectura de todos los destinos a visitar.

Asimismo, cada moleskine incluye funcionalidades $4 \mathrm{G}$ y un chip incorporado. Esto, sumado a la utilización de mapas offline, y a tener geolocalizadas mediante coordenadas exactas la totalidad de las obras de arquitectura reseñadas, conforma una herramienta de uso capaz de permitir:

- la posibilidad de conocer la ubicación propia en cualquier parte del planeta, solo con un chip telefónico sin necesidad de tener conexión de datos;

- $\quad$ visualizar las obras de arquitectura y lugares de interés y poder dirigirse hacia ellas sin conocer direcciones, o nombres de calles;

- $\quad$ acceder a contenidos académicos digitales interactivos residentes en el dispositivo (guías de viaje, lecturas recomendadas, etc.);

- lograr la autonomía casi completa en cuanto a localización y movimientos;

- tener una herramienta de comunicación en Internet mediante conexión WiFi;

- acceder a una base de datos de libros digitales, películas, música y otros contenidos digitales de uso recreativo;

- y finalmente, reemplazar cerca de siete quilogramos de papel por un único dispositivo de trescientos gramos.

Cada moleskine digital fue cargado individualmente con todos los insumos descriptos, pudiéndose verificar la completitud de la información entregada, en todos sus formatos y tópicos. El equipo utilizado fue de la marca española BQ, modelo Elcano 2 de $32 \mathrm{~Gb}$ internos, pues cumplía con todas las prestaciones exigidas a priori por las condiciones del proyecto.

\section{M2. Estudiantes en viaje (a escala grupal)}

Tradicionalmente, el Viaje de Arquitectura se realiza en pequeños grupos de cinco o seis viajeros, que conforman una unidad llamada "vehículo de viaje". Cada vehículo solía orientarse a través de guías de rutas, y las guías impresas. Dentro del proyecto académico Plexo, se instrumentó la adquisición previa al viaje de una unidad GPS por cada vehículo, con todas las obras de arquitectura y lugares de interés precargados y vinculados con la referencia de las guías. Es decir, como POIs georreferenciados dentro del dispositivo.
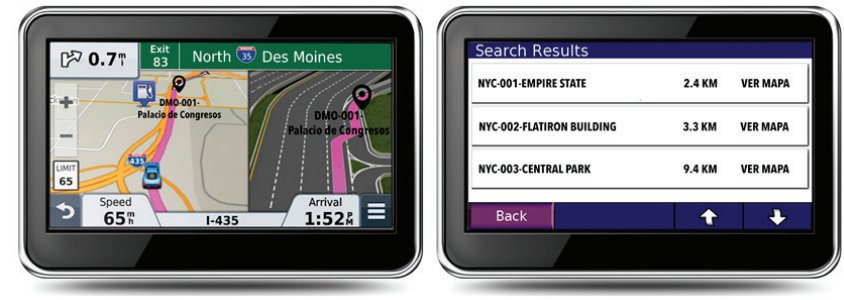

Figura 2: Unidad GPS personalizada por cada vehículo con todos los POIs ingresados.

De este modo, se pudo independizar por completo cada unidad vehicular, y definir un grado mucho mayor de autonomía de cada grupo. Es posible afirmar que en el estado actual de las cosas, y por primera vez, el 100\% de la información académica difundida y producida por y para el viaje de estudios, es de carácter digital.

\section{M3. Contexto universitario y público en general}

Parael contextoacadémicointra einter universitario, así comopara el público en general, se previeron tres instrumentos esenciales, que se contienen unos a otros, como tres círculos concéntricos: 
Deestemodo, se pudo independizar por completo cada unidad vehicular, y definir un grado mucho mayor de autonomía de cada grupo. Es posible afirmar que en el estado actual de las cosas, y por primera vez, el 100\% de la información académica difundida y producida por y para el viaje de estudios, es de carácter digital.

\section{M3. Contexto universitario y público en general}

Parael contextoacadémicointra einter universitario,asícomopara el público en general, se previeron tres instrumentos esenciales, que se contienen unos a otros, como tres círculos concéntricos:
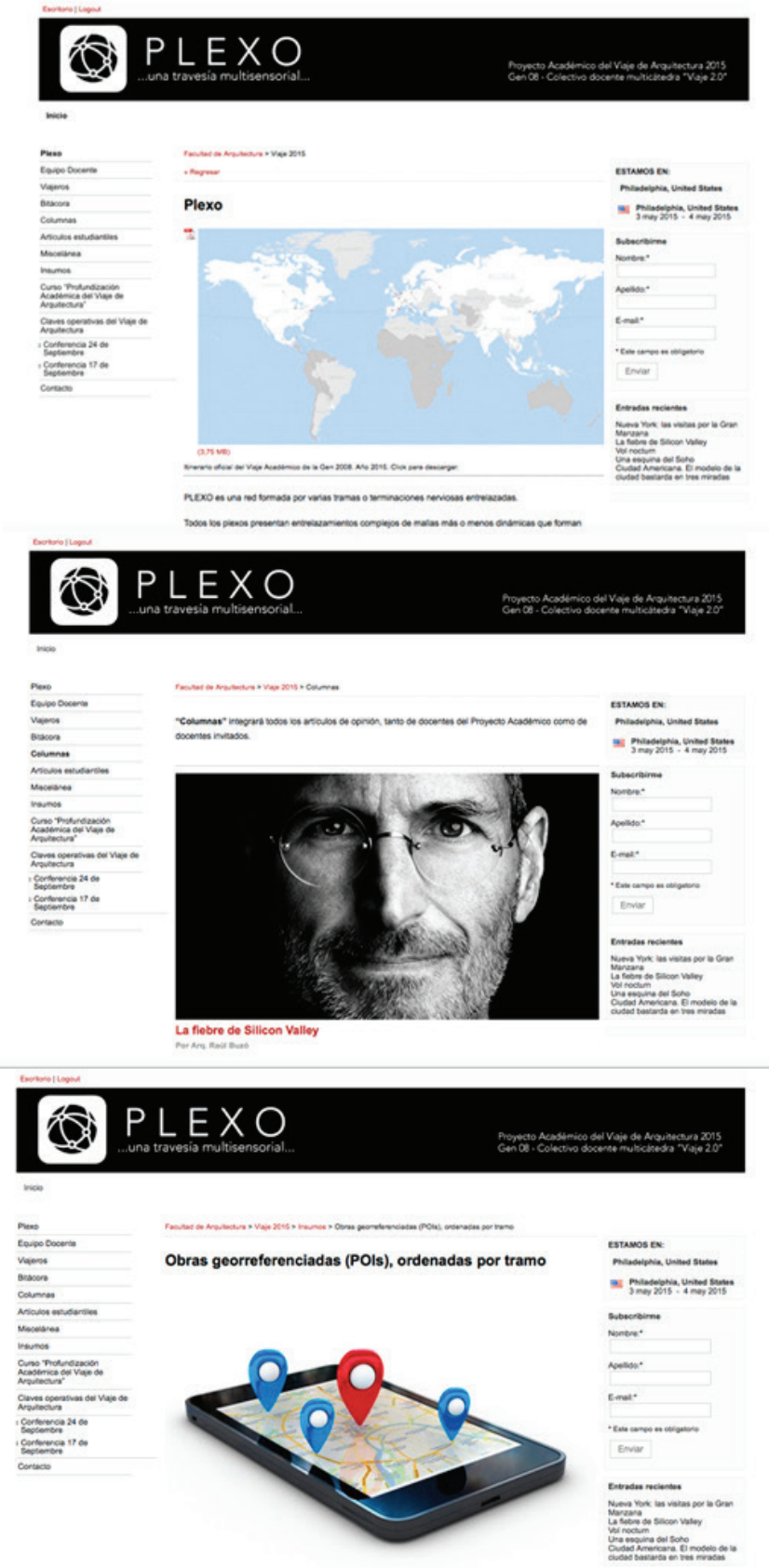

Figura 3: Capturas de pantalla de la web.
- $\quad$ Plataforma web central. La misma, que puede visitarse en www.plexo.edu.uy, nuclea todos los insumos necesarios para el viaje. Desde aplicaciones (apps) del proyecto para iOS y Android, mapas para descarga, puntos de interés (POIs) para GPS, georreferencias de obras para las tablets, y guías interactivas de viaje.

- $\quad$ Proyecto editorial. Este punto refuerza la idea de plataforma web, y está contenido dentro de esta. El proyecto editorial apunta a la redacción y distribución de artículos científicos, columnas de opinión, y difusión de los trabajos realizados por los estudiantes dentro del régimen curricular del viaje. Mediante esta acción, se promueve la plataforma web como un verdadero portal académico al servicio del Viaje de Arquitectura.

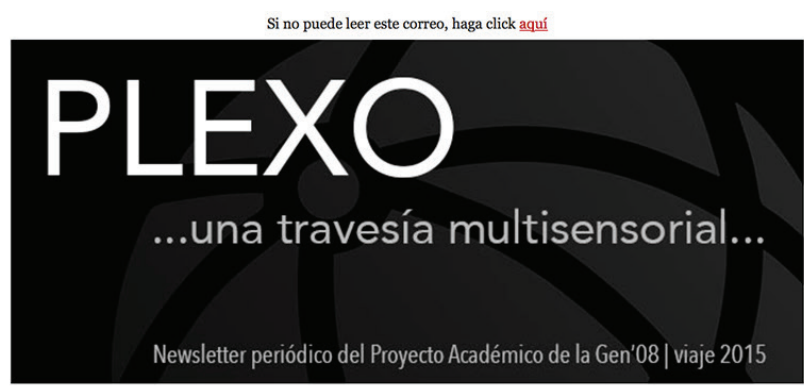

E

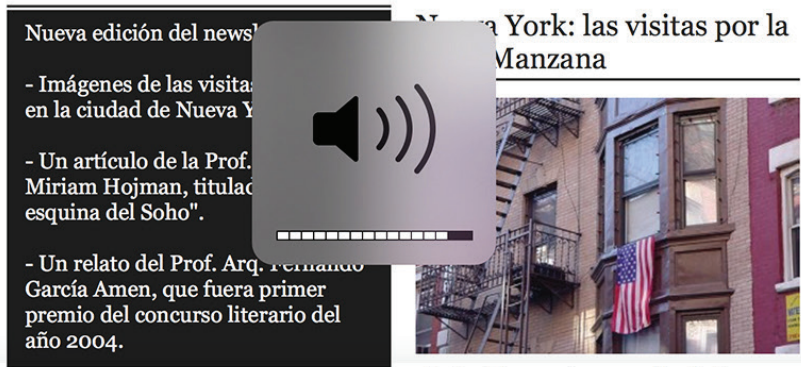
año 2004.

Menudencio Minucio. El

En los fríos pero intensos días de New hombre y el mito York, los dos contingentes de estudiantes finalmente pudieron unirse en un único..

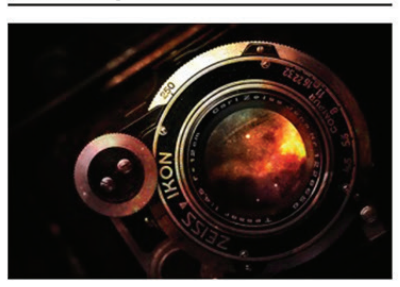

Prólogo. Tras el rastro de Menudencio, diez años después. [1] Nada hace dudar más de la Historia que el... continuar leyendo

Una esquina del Soho

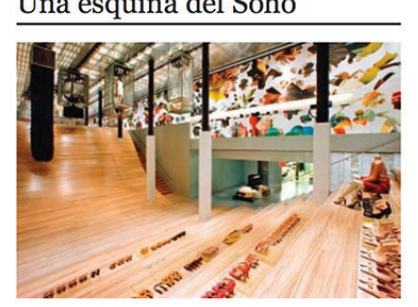

En 1998, año que conocí Nueva York, en la esquina de Broadway y Prince en el SoHo de Manhattan, se... continuar leyendo

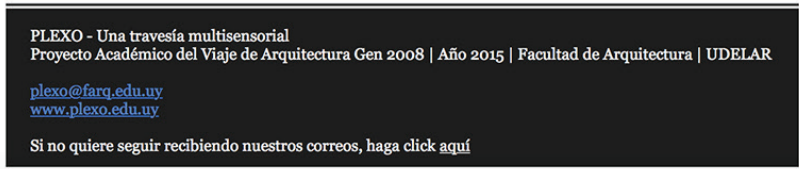

Figura 4: Captura del newsletter, a modo de ejemplo, mostrando el diseño de y contenido de cada entrega por suscripción. 
- Newsletters periódicos. Con un ritmo semanal, y con algunas ediciones especiales, las noticias, columnas, bitácoras, imágenes, recomendaciones generales y otros recursos informacionales son distribuidos mediante un boletín al que están suscriptos no solo los estudiantes viajeros sino también sus familias, gente del entorno académico, y público en general. La opción de registro es libre y abierta.

\section{Resultados obtenidos}

Si bien los resultados obtenidos podrán ser mensurables recién al finalizar el proyecto, corresponde referir a las expectativas que hoy por hoy se han generado a raíz del mismo:

- optimizar la accesibilidad a la información en entornos socioculturales diversos;

- optimizar tiempos de acción frente a la toma de decisiones de viaje;

- fomentar el uso de las tecnologías de la información en un contexto educativo completamente diverso y alejado de los cánones educativos tradicionales;

- centralizar la información académica en soportes digitales;

- $\quad$ profundizar en el incipiente paradigma de la lectura digital, colaborando así con el medioambiente al evitar la impresión de nada menos que 8.840.000 páginas-papel;

- permitir el acceso universal al producto académico generado al interno de la Facultad de Arquitectura de la Universidad de la República para este y para futuros viajes; y finalmente

- divulgar el fenómeno cultural único conocido como Viaje de Arquitectura, de modo de estimular a otras universidades para replicar esta experiencia formativa.

Quedan para el acervo documental de la Universidad de la República las guías de arquitectura revisadas y corregidas de treinta y cuatro países que conformaron el itinerario del viaje del año 2015; los contenidos editables de las mismas, en versión libre tanto en textos como en imágenes; todas las imágenes empleadas con sus respectivos créditos (por lo general, estudiantes de viajes previos); y el bagaje cognitivo general en relación al know how del proyecto.

La evaluación final deberá realizarse en los meses de Marzo y Abril del año próximo, en forma conjunta entre estudiantes, docentes y demás actores involucrados en la dinámica del viaje.

La versión consultable y abierta al público del proyecto puede ser visualizada a través de la web del mismo, localizable en http://www.plexo.edu.uy/.

\section{Debate}

La confección de guías de viaje actualizadas, con información fidedigna y fuentes contrastables para treinta y cuatro países, y más de tres mil quinientas obras de arquitectura es, sin lugar a dudas, un trabajo inmenso y descomunal. Insumió varios meses de búsqueda y trabajo colaborativo realizado por el Equipo Docente Director y el cuerpo estudiantil. Pudo constatarse, entre las dificultades metodológicas enfrentadas, la ausencia de contenidos previos abiertos y reutilizables, que pudiesen fungir a manera de base o sustrato sobre el cual cimentar el nuevo constructo teórico-práctico del proyecto propuesto. Debido a esto, su puesta en marcha fue sensiblemente más compleja de lo previsto.

Corresponde acaso preguntarse, al asumir esta tarea, el por qué de su no instrumentación sistemática de modo de lograr un modelo crítico-acumulativo del conocimiento. Quizá las razones sean más estructurales que filosóficas, y por ello es necesaria una reformulación drástica de las redes tradicionales del conocimiento hasta ahora empleadas.

Es intención de este trabajo, luego de ser completado, evaluado y validado en su integralidad, forjar un debate serio al interno de la estructura académica, y avanzar en la construcción de este "repositorio digital", no solo como un proyecto académico puntual sino como una construcción capaz de trascender nombres, cátedras y equipos, para constituirse en una poderosa herramienta de soporte al tradicional viaje de estudios desde una óptica de creación abierta y colectiva.

\section{Agradecimientos}

A toda la Generación 2008 del Grupo de Viaje de la carrera de Arquitectura de la Universidad de la República, por confiar en este colectivo docente para llevar adelante el Proyecto Académico del año 2015.

\section{Referencias}

García Amen, F.; Payssé, M.; Portillo, J.P.; Richero, A.; (2011). Viaje 2.0; Un moleskine digital, SIGRADI Proceedings. Santa Fe, 2011.

Barrán, P.; García Amen, F. (2013). Viaje 2.0. Primera curricularización del Viaje de Arquitectura. UDELAR, Montevideo, 2013.

Carretero Díaz, M.; Hermosilla, J. Gestión y generación del conocimiento mediante el uso de plataformas digitales de formación. En Revista Complutense de Educación. Vol.15 No.1. UCM. Madrid, 2015.

Keefer Riva, A. Los repositorios digitales universitarios y los autores. Anales Universidad de Barcelona. No 10, 2007, PÁGS. 205-214 